\title{
O Professor e a Arte de Avaliar no Ensino Médico de uma Universidade no Brasil
}

\section{The Teacher and the Art of Evaluating in Medical Teaching at a University in Brazil}

\author{
Marlene Harger Zimmermann \\ Rosemari Monteiro Castilho Foggiatto Silveira ${ }^{I I}$ \\ Ricardo Zanetti Gomes
}

\section{PALAVRAS-CHAVE}

- Feedback.

- Avaliação Educacional.

- Educação Médica.
I Universidade Estadual de Ponta Grossa, Ponta Grossa, Paraná, Brasil.

II Universidade Tecnológica Federal do Paraná, Ponta Grossa, Paraná, Brasil.
A avaliação é intrínseca ao ato de ensinar e uma possibilidade de ampliar e melhorar o conhecimento adquirido pelo aluno. No ensino na área da saúde, a avaliação possui peculiaridades e requer constante diálogo com os docentes e discentes a fim de receber aprimoramentos. O objetivo deste estudo foi traçar um diagnóstico inicial do processo avaliativo no curso de Medicina de uma instituição de ensino superior pública no Estado do Paraná, sob a perspectiva de professores e alunos. Trata-se de um estudo exploratório, de abordagem metodológica qualitativa, de natureza interpretativa, realizado com 22 professores e 20 alunos do internato de Clínica Médica. A coleta de dados deu-se de novembro de 2015 a fevereiro de 2016, com entrevista semiestruturada, de caráter individual, que foi gravada e transcrita literalmente. Foi empregada análise de conteúdo para examinar os dados, que foram decodificados e agrupados por similaridade de assuntos, tendo emergido quatro categorias de análise. Os resultados mostram que os participantes do estudo apontaram dificuldades na avaliação. Em relação aos docentes, foi mencionada a necessidade de formação didático-pedagógica e em avaliação de habilidades, estratégias para aprimoramentos em feedback, em autoavaliação do aluno e na padronização do processo avaliativo realizado pelos docentes. O médico professor percebe-se como aprendiz neste processo e tem a percepção de que a falta de domínio pedagógico para aprender e melhorar sua avaliação gera a necessidade de formação. Conclui-se que, na arte de avaliar, a participação dos professores e alunos se torna importante estratégia para ajustes e melhorias. As reflexões sobre o papel dos atores no cenário do ensino são benéficas para a formação de ambos, pois juntos compartilham olhares, percepções e sugestões, rumo ao ensino e ao aprendizado de excelência. O feedback, a autoavaliação e a padronização constituem elementos singulares e colaboram com o processo avaliativo. 


\section{KEY-WORDS}

- Feedback.

- Educational Evaluation.

- Medical Education.

Recebido em: 16/12/18

Aceito em: 12/2/19

\begin{abstract}
Evaluation is intrinsic to the act of teaching and a possibility to increase and improve the knowledge acquired by the student. In health education, assessment has peculiarities and requires constant dialogue between teachers and students in order to achieve improvements. The objective of this study was to draw up an initial diagnosis of the evaluation process in the medical course of a Public Higher Education Institution of the State of Paraná, from the perspective of teachers and students. This was an exploratory study, with a qualitative methodological approach, and of an interpretative nature, performed with twenty-two (22) teachers and twenty (20) medical intern students. Data collection took place from November 2015 to February 2016, with a semi-structured interview of an individual character that was recorded and transcribed verbatim. The data were analyzed by content analysis, which were decoded and grouped by subject similarity, from which four categories of analysis emerged. The results show that the study participants pointed out difficulties in the evaluation; teachers were mentioned: the need for didactic-pedagogical training and the evaluation of skills, strategies for improvements in feedback, self-assessment of the student and the standardization of the evaluation process conducted by the teachers. It is concluded that in the art of evaluation, the participation of teachers and students becomes na important strategy for adjustments and improvements. Reflections on the role of actors in the educational setting are beneficial to the formation of both. The inclusion of feedback, self-assessment and standardization are unique elements and collaborate with the evaluation process.
\end{abstract}

\section{INTRODUÇÃO}

A avaliação, para cumprir seu verdadeiro significado, não pode ser pensada desconectada do processo de ensino-aprendizagem, tendo em vista servir de guia e suporte para solucionar os problemas de aprendizagem. Estratégias como a autoavaliação e o feedback podem colaborar na execução da difícil tarefa representada pelo ato de avaliar. A avaliação deve incluir as habilidades cognitivas e motoras, bem como os comportamentos e atitudes, preocupando-se com o desenvolvimento de competências ${ }^{1}$.

Nesse sentido, as Diretrizes Curriculares Nacionais (DCN) aprovadas para o curso de Medicina em 20/06/2014 estabelecem que a avaliação deve ser baseada em competências, habilidades e conteúdos curriculares. Ademais, deve contemplar não só o conhecimento adquirido, como também habilidades específicas. O Objective Structural Clinical Examination (Osce) vem ao encontro dessa necessidade, por se tratar de uma avaliação estruturada e objetiva de casos clínicos simulados, que se traduz em "mostrar como se faz". Pode-se considerá-la uma alternativa às dificuldades constatadas com os instrumentos tradicionais de avaliação, como prova oral, prova escrita e testes de múltipla escolha ${ }^{2-3}$.

$\mathrm{O}$ aluno no ensino médico necessita ser avaliado por um instrumento ou um modelo de avaliação que apresente questões que exijam dele a demonstração de habilidades e atitudes na resolução de problemas clínicos. Portanto, a padronização estruturada ganha espaço e torna-se um importante instrumento na tentativa de auxiliar as avaliações, em busca de homogeneidade do processo avaliativo, principalmente em relação às habilidades e atitudes.

Nessa metodologia, ganha destaque o feedback, que passa a ser uma significativa ferramenta de ensino, de aprendizagem e de avaliação, tendo o intuito de modificar o pensamento ou comportamento do aluno com a finalidade de melhorar sua aprendizagem e evitar a repetição de erros ${ }^{4}$.

Para a avaliação do ensino e da aprendizagem, criou-se, em 1991, a Comissão Interinstitucional de Avaliação das Escolas Médicas (Cinaem). Uma de suas avaliações evidenciou como um dos problemas o sistema de avaliação docente e discente, sendo as avaliações de aprendizagem de caráter terminal, centradas na memorização, sem contemplar as habilidades e atitudes na aplicação do conhecimento ${ }^{5-6}$.

Neste estudo, pesquisou-se um curso de Medicina de uma instituição de ensino superior (IES) no Estado do Paraná que há dez anos vem formando novos médicos. Seu quadro de docentes é formado, em sua maioria, por médicos que não possuem formação pedagógica com conhecimentos específicos na área de licenciatura, o que gera dúvidas na questão de como ensinar e avaliar no ensino da saúde. 
Diante dessa problemática, observou-se a necessidade de ouvir professores e alunos desse curso no intuito de se obter uma avaliação diagnóstica do processo avaliativo efetuado. Parte-se do pressuposto de que toda avaliação, no sentido de reflexão crítica acerca da realidade, deve servir como guia e suporte para solucionar as necessidades de aprendizagem do discente, aumentar sua autoconfiança, possibilitar a reconstrução do processo de ensinagem e apontar caminhos para o docente em seu processo avaliativo. Para isso, é importante conhecer a realidade por meio do diagnóstico, pois os resultados podem auxiliar na elaboração de ações, colaborando para o aperfeiçoamento da avaliação. Portanto, o objetivo deste estudo é traçar um diagnóstico inicial do processo avaliativo no curso de Medicina de uma instituição de ensino superior pública do ponto de vista dos docentes e alunos.

\section{MÉTODO}

Trata-se de um estudo exploratório, com abordagem qualitativa de natureza interpretativa, realizado com docentes e alunos de um curso de Medicina. Foram convidados todos os 50 docentes que atuavam com supervisão na disciplina de Internato da sexta série desse curso, os quais se dispuseram a participar. Todos os 20 alunos matriculados na disciplina dos Internatos de Pediatria e de Clínica Médica foram convidados e concordaram em participar do estudo.

A escolha dos sujeitos do estudo foi por conveniência, sendo que com os docentes as entrevistas terminaram ao atingirem saturação teórica dos dados, ou seja, com 22 docentes. Saturação teórica é o critério para julgar quando cessar a amostragem dos diferentes grupos pertinentes a uma categoria ${ }^{7}$.

A coleta de dados dos participantes deu-se por meio de entrevistas semiestruturadas, de forma individual, as quais foram gravadas e transcritas literalmente. $\mathrm{O}$ protocolo de entrevista dos docentes e discentes constituiu-se de dois blocos, sendo que no bloco A foram registrados dados de identificação, e no bloco B, perguntas relativas à avaliação realizada no curso a saber: utilização de algum instrumento/estratégia para avaliação, uso de autoavaliação, prática do feedback, sugestões de como a avaliação deveria ser, o que pensa sobre o Osce e se faz uso dele.

Para a coleta de dados com os professores, foram agendados, com cada um, horário e local que melhor lhes conviessem. A coleta de dados com os alunos foi realizada nas dependências de dois hospitais. Após esclarecimentos e assinatura do TCLE, os dados foram coletados.

A coleta de dados ocorreu entre novembro de 2015 e fevereiro de 2016. Houve transcrição literal das gravações, e, após a validação pelos participantes do estudo, os dados fo- ram analisados por meio da análise de conteúdo, definida por $\operatorname{Bardin}^{8}$ (p. 38) como "um conjunto de técnicas de análise de comunicações, que utiliza procedimentos sistemáticos e objetivos de descrição do conteúdo das mensagens". Obedeceu-se às fases de pré-análise, em que houve escolha dos documentos para a formação do corpus; exploração do material, cujas unidades de registro e de contexto emergiram; categorização, com a criação das categorias; e a fase de análise dos dados propriamente dita, fazendo-se uso da interpretação dos achados.

Este estudo apresenta os resultados iniciais de pesquisa de doutoramento, cujo projeto de pesquisa recebeu parecer de aprovação 109336/2015 e registro na Plataforma Brasil CAAE 50489415.6 .0000 .0105$.

\section{RESULTADOS}

O número de participantes docentes do sexo masculino foi de $54,60 \%$, e o do sexo feminino foi de $45,40 \%$. Apenas um dos professores tem menos de dez anos de atuação na profissão médica; em relação à docência, 10\% têm experiência de dez anos ou mais.

Os professores participantes deste estudo têm bom tempo de formados, o que lhes confere experiência como profissionais médicos. Contudo, ainda estão se adequando às necessidades da profissão docente, pois o contato com o ensino e com seus aspectos pedagógicos é bem-vindo e pode minimizar as dificuldades do professor que não tem formação inicial na área do ensino, sendo designado como "estrangeiro" nesta expertise ${ }^{9}$.

O universo dos docentes é composto por profissionais oriundos de nove IES, com destaque para a Universidade Federal do Estado do Paraná, com $45,45 \%$ dos professores, e de cinco estados (Paraná, Santa Catarina, Rio Grande do Sul, Rio de Janeiro e Pará), destacando-se o Estado do Paraná com $72,72 \%$.

Essa pluralidade dos diferentes locais do Brasil na formação inicial dos profissionais médicos é fator positivo, tendo em vista que as múltiplas experiências obtidas nos diferentes centros formadores constituem um rico aprendizado teórico e prático, que pode ser transposto para a sala de aula em uma diversidade de interações.

Quanto ao perfil dos alunos, mais da metade deles (65\%) era do sexo masculino e $35 \%$ do sexo feminino.

A oportunidade dada aos alunos para expressarem suas opiniões sobre o ensino e a aprendizagem oferecidos no curso de Medicina reforça a importância da participação do aluno em sua formação. Ouvir e valorizar as opiniões dos atores no cenário do ensino é fundamental, pois possibilita reflexões no campo das práticas avaliativas, podendo constituir uma im- 
portante ferramenta para possíveis mudanças no cotidiano escolar ${ }^{10}$.

Da análise dos dados emergiram quatro categorias de análise que trazem o diagnóstico inicial da percepção dos docentes e alunos participantes da pesquisa em relação ao processo avaliativo efetuado em seu curso.

\section{O professor e o ato de avaliar}

Esta categoria evidencia aspectos relevantes sobre a avaliação que permeia o ensino e a aprendizagem.

Ao serem indagados sobre como eram avaliados e por quais instrumentos e estratégias, quase metade dos alunos (45\%) afirmou que a avaliação ocorria por meio de diferentes procedimentos e instrumentos (prova prática com uso de simulações, prova teórica, prova oral, seminários, avaliação atitudinal - relativa ao relacionamento com o professor e com os pacientes -, Mini Clinical Examination e Osce). Dos instrumentos e procedimentos avaliativos apontados pelos alunos, salienta-se a importância da avaliação atitudinal, que muitas vezes é negligenciada pelo educador em comparação à avaliação cognitiva e de habilidade técnica. Tratando-se de formar profissionais que respeitem o outro e se coloquem no lugar dele, é preciso estimular as relações que proporcionem condições de vivenciar tal comportamento. Aprende-se por meio da atividade, do movimento e, de acordo com Luckesi ${ }^{11}$ (p. 82-83), "o movimento, à medida que é praticado, organiza a experiência, o que significa estruturar nova forma para um novo modo de ser e de agir. [...] Por meio de atividades reiteradamente realizadas, vamos organizando para nós mesmos um modo constante de agir". Portanto, o exercício da interação com o paciente e familiares deve ser praticado e avaliado na formação inicial.

Esses instrumentos/estratégias também foram ressaltados por quase a totalidade $(95,45 \%)$ dos docentes, que reiteraram a diversidade de instrumentos (figuras) e procedimentos avaliativos (seminários) empregados em diferentes momentos formativos. Avaliações teóricas e práticas são realizadas junto ao paciente real, à beira do leito (Miniex). A avaliação de habilidades (Osce) foi executada somente uma vez em um dos internatos, envolvendo cinco professores. A avaliação atitudinal, que envolve atitude, comprometimento, comportamento, relação interpessoal, relação com o paciente, pontualidade, assiduidade e interesse do aluno, também foi mencionada pelos docentes.

Neste estudo, a simulação aparece fazendo parte do cenário avaliativo na tentativa de transferir realismo ao aluno durante sua avaliação. Para os estudantes deste estudo, a simulação com uso de manequins tem sido um recurso interessante, que, além do realismo, auxilia também na fixação dos procedimentos. Os professores devem usar diferentes estratégias de avaliação e em contextos mais próximos de situações da vida real, dando espaço para a simulação clínica, que ganha relevância e deve ser incorporada como uma forma de avaliar os alunos $^{12}$

Observou-se também que a participação do docente na formação é diversificada. Ele lança mão de diversos métodos e instrumentos com aplicação em diferentes momentos do processo de ensino e de aprendizagem, valorizando a avaliação formativa. De igual forma, preocupa-se em avaliar o aluno em suas múltiplas dimensões, envolvendo os aspectos cognitivos, atitudinais, relacionais e as habilidades técnicas. A avaliação do acadêmico de Medicina "deve contemplar não só o conhecimento adquirido, mas também habilidades específicas e elementos de ordem afetiva, como as atitudes frente aos inúmeros aspectos da prática profissional"13 (p. 429).

Essas múltiplas dimensões são imprescindíveis à formação do profissional médico, tendo em vista que a relação que se dá no atendimento à saúde acontece entre pessoas, ou seja, entre o médico, o paciente e seus familiares. Portanto, a dimensão humana não pode ser negligenciada, tornando-se de extrema necessidade nesse contexto. Afinal, a habilidade relacional, na qual a comunicação se manifesta, é uma das competências para a formação do clínico médico, de acordo com a câmara técnica do Conselho Federal de Medicina do Brasil ${ }^{14}$.

Alguns alunos (30\%) citaram que as provas teóricas são elaboradas de diferentes formas (descritiva, múltipla escolha, somatória, discursiva, questão 1 e 2 corretas, mescladas com questões objetivas e subjetivas) para obter um valor quantitativo, no caso, uma nota exigida pela instituição de formação. Apesar das diferentes formulações das provas teóricas, em se tratando de um curso em que as DCN enfatizam aprendizado com participação ativa do aluno, o processo avaliativo poderia acompanhar essa diretriz incluindo nas avaliações a construção do portfólio. Este, além de ser uma avaliação formativa, possibilita que o aluno do ensino médico participe ativamente de sua avaliação, acompanhe seu progresso e reflita sobre seu aprendizado e suas lacunas ${ }^{15}$.

Entre os diversos procedimentos de avaliação, alguns docentes $(36,36 \%)$ afirmam que a prova teórica continua a liderar, e sua formulação tem sido bem diversificada, indo ao encontro do que os alunos afirmaram. Contudo, poucos alunos (10\%) consideram que as avaliações teóricas nem sempre avaliam o conhecimento. Algumas formulações geraram descontentamento dos alunos, principalmente no caso de cada tentativa falsa anular uma questão correta. Em relação a esse descontentamento, recorda-se que a avaliação da aprendizagem 
requer instrumentos que ampliem a capacidade do professor de observar a realidade sobre o desempenho do aluno. Lançando um olhar crítico sobre tais instrumentos, é importante refletir se estes são adequados aos objetivos a serem atingidos e "se apresentam as qualidades metodológicas necessárias de um instrumento satisfatório de coleta de dados para a prática da avaliação da aprendizagem"11 (p. 305).

Outro desvelamento encontrado refere-se ao aprendizado que permeia a intencionalidade de avaliar, tanto para alunos como para docentes, principalmente nas provas teóricas, uma vez que há uma preocupação de alcançar o aprendizado e não somente obter uma nota para ser aprovado. A avaliação da aprendizagem é um componente do ato pedagógico. Portanto, aprender em vez de somente obter uma classificação é o objetivo fundamental da prática educativa e avaliativa. Ela não pode ser praticada isoladamente, correndo o risco de se dissociar e perder sua dimensão pedagógica ${ }^{11}$. Apropriar-se do conhecimento oferecendo ao educando uma aprendizagem significativa, tendo em vista auxiliar a formação como sujeito e como cidadão inserido na sociedade, é o foco em que se deve investir na atividade pedagógica. Sob esse prisma repousa o ato avaliativo que assume um compromisso sobre a singularidade do ato de aprender com ampliação para as relações sociais ${ }^{2}$.

Além da pluralidade dos instrumentos avaliativos e de sua forma de elaboração, salienta-se que, neste estudo, a visão do docente relativa à complexidade e à profundidade que o ato avaliativo encerra possibilita o aprendizado, pois a “avaliação é uma oportunidade para 'melhorias' e não apenas como um resultado numérico"12 (p. 68). Esse aprendizado se faz por meio da conjunção de fatores, sendo um deles o papel do professor, que será o de mediador, ajudando o aluno, apoiando, corrigindo, propondo questionamentos sobre seu desempenho ${ }^{16}$, como também transmitindo experiência, conhecimento, habilidades e atitudes, ajudando o aluno a aprender a aprender. Essa interface com o ensino e a aprendizagem torna-se um valioso instrumento para o crescimento tanto de alunos como de professores. Ao avaliar sobre a aprendizagem do aluno, o professor está avaliando seu êxito na tarefa de ensinar, tendo a oportunidade de abandonar o lugar do sujeito que ensina e ocupar o lugar de quem aprende; com isso, tem a possibilidade de rever seu planejamento educacional e, se necessário, reorientar seu fazer docente. Já quanto ao aluno, a avaliação é feita para indicar o que é imprescindível à sua formação e reorientá-lo na aquisição das competências não alcançadas ${ }^{1}$. Por conseguinte, a avaliação deve ser considerada como inserida no processo de ensino e aprendizagem, pois este deve ser o seu real significado.
Notadamente, tanto alunos como docentes desejam que haja êxito na formação dos futuros médicos. Contudo, o fato de utilizar certa diversidade de estratégias nas avaliações e diferentes formas de elaboração das avaliações teóricas não garante ausência de fragilidades. Primeiro, porque avaliar sempre foi e sempre será um desafio e, segundo, porque os docentes, em tese, não possuem expertise em avaliação, pois são médicos professores e não professores médicos.

Alguns (36,36\%) docentes afirmaram ter dificuldade em avaliar, afirmando ainda que a prova não avalia adequadamente o conhecimento do aluno e que têm dificuldade na formulação da prova por falta de embasamento teórico para isto. Se as provas teóricas não forem bem formuladas, haverá o risco de não se atingir o propósito de avaliar o conhecimento do aluno, pois um instrumento mal elaborado não coleta os verdadeiros dados, impossibilitando que o docente tenha ciência da real aprendizagem efetuada e das lacunas que necessitam de aprimoramentos. Pela dificuldade apontada pelos docentes em construir o instrumento para avaliação, sobressai a importância de o docente participar de formações continuadas, com ênfase nos aspectos avaliativos.

Determinados alunos (30\%) e docentes (18,18\%) mencionaram que as avaliações carecem de uniformidade, rigidez, critérios, coerência e objetividade. Elas são também tradicionais, subjetivas, heterogêneas e não condizentes com a progressão do aluno. Há necessidade de rever a elaboração e correção das provas. Essas lacunas merecem revisão e reflexão por dificultarem e fragilizarem o processo avaliativo, podendo dar margem a dúvidas nas provas efetuadas, bem como a avaliações sem isenção por conta da subjetividade. Tratando-se de avaliação educacional, a validade, a fidedignidade, a viabilidade, a aceitabilidade e o impacto educacional são atributos fundamentais determinantes da qualidade da avaliação e necessitam ser incorporados no instrumento avaliativo elaborado pelo docente ${ }^{17}$.

A subjetividade na avaliação atitudinal foi citada como um problema por uma parcela de alunos (30\%) e docentes $(31,81 \%)$. Os alunos entendem que a subjetividade é terreno propício a avaliações injustas, e os docentes afirmam que ela dificulta o processo avaliativo principalmente quando a situação a ser avaliada requer objetividade.

A pesquisa traz como resultado, ainda, a falta e a necessidade de padronização na avaliação realizada no curso de Medicina, sendo apontadas pela grande maioria dos docentes $(77,27 \%)$ e parte dos alunos (15\%). As diferentes metodologias de ensino utilizadas pelos professores geram diferentes formas de avaliar em cada disciplina. Por essa razão, os participantes da pesquisa consideram importante que a avaliação 
seja padronizada. Entendem que quanto mais padronizado, menos desvio, quanto mais objetivo, menos viés, tendo em vista que a padronização ajudaria o professor a avaliar com isenção, evitando a subjetividade. Nesse sentido, o Osce pode ajudar nas lacunas encontradas na formação dos estudantes médicos, pois permite a avaliação de habilidades clínicas com maior grau de objetividade, maior e melhor padronização e sob observação direta ${ }^{17}$.

\section{O feedback no processo avaliativo}

Esta categoria aborda a devolutiva ao aluno sobre seu desempenho. Este estudo trouxe à tona a questão dessa imprescindível ferramenta avaliativa, o feedback, cujo objetivo é fortalecer a aprendizagem significativa e suscitar avanços na apreensão do conhecimento.

Esclarece-se que as disciplinas teóricas do curso de Medicina em estudo são compostas também por atividades práticas. Portanto, as avaliações do aprendizado são realizadas por meio de provas teóricas e práticas, tornando-se momentos oportunos de que os docentes dispõem para realizar o feedback.

$\mathrm{O}$ uso do feedback foi considerado importante por mais da metade dos alunos (60\%). No estudo, sobressai a questão do direito do aluno de saber sobre seu desempenho e a oportunidade de discutir sobre suas dificuldades e erros, visando melhorias em seu aprendizado, tendo em vista que o erro é também fecundo para consolidar o conhecimento rumo ao correto. Para os discentes, as pessoas aprendem e gravam com o erro, e este assume diferentes conotações: ora como um conhecimento e sua análise, uma metodologia de ensino, pois pode ser usado como fonte de novas descobertas; ora com a conotação de estratégia didática que considera o erro e o acerto como importantes elementos integrantes do processo de aprendizagem em que o erro pode contribuir para melhorias no ensino ${ }^{18,19}$. Para isto, o professor deve mudar a sua postura epistemológica, deixando de considerar o erro como uma incapacidade do aluno, para uma postura construtiva, que busca desvendar o obstáculo epistemológico que impede a aprendizagem do aluno.

O feedback foi apontado como importante por grande número de docentes $(54,54 \%)$ e considerado fundamental para perceber a natureza do caminho que o aluno elaborou na apreensão do conhecimento. Nesse sentido, "os docentes desempenham um papel fundamental no desenvolvimento das capacidades próprias de autorregulação dos estudantes, constituindo-se uma fonte fundamental de feedback ${ }^{\prime \prime 20}$ (p. 121). Na concepção de poucos professores (9,09\%), o feedback é também importante para a autoavaliação do fazer docente em busca de aprimoramentos. Salienta-se que, na relação pedagógica que se dá entre aluno e professor, ambos são responsáveis pelo sucesso ou insucesso da aprendizagem do aluno. A parte que cabe ao professor está relacionada à metodologia empregada, às estratégias de ensino usadas, às formas de avaliação selecionadas, à relação estabelecida entre aluno e professor (autoridade e não autoritarismo), que podem constituir importantes constructos autoavaliativos para melhorar a prática docente.

Outrossim, a participação ativa do aluno na construção do seu conhecimento tem sido cada vez mais enfatizada, e o feedback vai ao encontro dessa demanda, tornando-se uma rica ferramenta nas mãos do docente, incentivando o aluno, mostrando o caminho, suscitando reflexões para ambos os atores no cenário da educação.

Embora o feedback seja apontado como importante e realizado, em geral, de forma grupal nas avaliações teóricas, alguns docentes $(13,63 \%)$ e alunos $(25 \%)$ afirmaram que ele não ocorre nas provas teóricas. $\mathrm{O}$ aluno tem conhecimento de sua nota, que, na maioria das vezes, é enviada por e-mail e lançada no sistema de que a universidade dispõe, mas não sabe o que errou ou acertou. $\mathrm{O}$ discente, muitas vezes, recebe a nota, não concorda com ela, mas não recebe feedback do professor para discutir. Quando as notas são lançadas sem que haja entrega do instrumento avaliador nas mãos do aluno, ele só pode revê-la fisicamente se fizer solicitação formal.

Os docentes que lançam as notas das avaliações no sistema por e-mail sem que os alunos revisitem o instrumento de avaliação ou que só permitem vistas da prova mediante protocolização assumem uma postura um tanto contrária ao processo de ensino e de aprendizagem do aluno. Corrigir, de igual forma, é abrir-se, dando espaço a percorrer o caminho de construção elaborado pelo aluno na devolutiva sobre o conhecimento adquirido. Para isso, a visualização da prova é condição sine qua non para sujeitos aprendentes e ensinantes, pois, afinal, avaliar é estar também em avaliação. A avaliação da aprendizagem pressupõe investigação e intervenção, porque "investigar para conhecer e conhecer para agir são dois algoritmos básicos para a produção de resultados satisfatórios O contrário disso é: sem investigação, não se tem conhecimentos, e, sem conhecimentos, não se tem eficiência e qualidade"11 (p. 149).

Entre os poucos professores que fazem a devolutiva da prova teórica de forma individual e o mais breve possível, é a postura que se enquadra como a mais recomendada. Nesse sentido, ao planejar as aulas, o professor deve prever espaço para a devolutiva da prova corrigida e a visualização do aluno quanto aos seus erros/acertos, preferencialmente num momento próximo da avaliação realizada. A devolutiva individual, além de não expor as lacunas do conhecimento do 
aluno aos demais, é direcionada as suas necessidades, o que pode ser mais efetivo.

Nesse sentido, o professor necessita repensar sua postura para que ambos sejam beneficiados. $\mathrm{O}$ aluno tem o direito de expor ao docente o caminho percorrido na devolutiva do conhecimento apreendido e a oportunidade de "dialogar" com suas lacunas. Por outro lado, o docente tem o dever de exercer com maestria o que lhe cabe, que é mostrar ao aluno quando este está equivocado. Às vezes, o equívoco vem do próprio professor, e este, ao acolher a opinião do aluno, ainda lhe ensina que a humildade é sempre bem-vinda. Aqui não cabe o autoritarismo, que afastará o diálogo enriquecedor entre professor e aluno. Como expressa Cortella ${ }^{21}$, só pode ser um bom ensinante quem for um bom aprendente, e quem não conseguir ser um bom aprendente não conseguirá ser um bom ensinante. $\mathrm{O}$ autoritarismo, muitas vezes, macula a autoridade, e ambos não devem ser confundidos, principalmente no ensino, em que os atores do processo de formação necessitam de proximidade.

Em relação ao feedback, apesar de ser considerado importante pelos participantes e realizado nas disciplinas teóricas e práticas (internato) de forma individual ou grupal, ele não é valorizado como deveria e não é também uma prática hegemônica entre a grande maioria dos docentes. Para que o aluno e o docente possam aprender com o erro, como foi lembrado pelos participantes do estudo, é necessário que eles tenham ciência de suas lacunas por meio do feedback, além da condição intrínseca (humildade e reflexão) para ajustes necessários. Os dados obtidos neste estudo demonstram, com clareza, que a avaliação está intrinsecamente unida ao processo de ensino e de aprendizagem, pois também se aprende com o erro, e há uma solidificação do que é correto, contribuindo para evitar que o erro se repita.

Além de o aluno ter consciência, por meio do feedback, do erro cometido, essa devolutiva da avaliação também é um recurso que permite ao aprendiz monitorar sua aprendizagem em busca da aprendizagem significativa para um bom desempenho profissional, em vez de alcançar uma nota somente para ser promovido de série.

$\mathrm{O}$ aluno, ao considerar o feedback um estímulo, um incentivo a sua dedicação, bem como um reforço de seus aspectos positivos na aprendizagem, possibilita ao docente repensar sobre o quanto essa devolutiva é importante. Esse retorno dos aspectos positivos é, muitas vezes, negligenciado e até esquecido pelo docente. Especificamente no ensino médico, a quantidade de conteúdo é tão extensa e densa que um feedback positivo pode trazer importantes benefícios ao aluno em seus aspectos emocionais e motivacionais.
Além das disciplinas teóricas, há o internato, que é uma disciplina prática oferecida nos últimos dois anos da formação. Nela também, o feedback docente é apontado como não realizado pela metade $(50 \%)$ dos alunos. Em contrapartida, quase a metade $(40 \%)$ dos docentes afirmam que o fazem. Essa divergência verificada entre os participantes do estudo provavelmente está associada às provas práticas realizadas no internato fora do método Osce (realizado apenas uma vez com três professores) e outras dentro desse método. Os alunos afirmam que, também no Osce, o feedback não é realizado de maneira efetiva.

Entre os espaços de formação, o internato é privilegiado e importante para o feedback, mas nem todos os docentes colocam em prática essa devolutiva. Verificou-se que não há uma uniformização das condutas relativas ao feedback para o aluno. Alguns o fazem de forma individual ou grupal, mas outros acabam deixando passar a rica oportunidade de o aluno revisitar o que foi feito com a intenção de aprimorar o aprendizado, evitando a repetição dos erros que porventura ocorreram.

Nesse contexto, o feedback, além de ser uma forma de estimular e incentivar o aluno, pode também auxiliar na retenção do conteúdo. Com base na experiência vivenciada pelo aprendiz graças à devolutiva do seu desempenho, ele tem a oportunidade de relacionar os saberes docentes com os aprendizados discentes, resultando na fixação dos conteúdos mais relevantes. O feedback tem importante implicação para o ensino médico, pois "configura-se como um componente essencial no desenvolvimento da prática reflexiva e da construção do

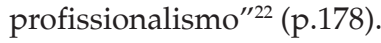

O feedback está intrinsecamente relacionado à autoavaliação, uma vez que a devolutiva suscita no aluno uma reflexão e aceitação sobre o desempenho comentado pelo docente. Sendo assim, a autoavaliação surge como um importante elemento avaliativo e será abordada como próxima subcategoria.

\section{Autoavaliação}

Esta categoria refere-se a um exercício de reflexão valioso para redefinir estratégias para o alcance dos objetivos que se pretende atingir.

Quando foi perguntado aos participantes da pesquisa se achavam importante a autoavaliação, muitos alunos $(77,77 \%)$ e docentes (63,63\%) afirmaram que sim. De maneira geral, os alunos têm a percepção de que a autoavaliação pode ajudar como uma reflexão acerca do desempenho rumo à excelência do aprendizado, tornando-se a voz da consciência do aluno. Houve, inclusive, uma sugestão de que um roteiro com critérios para esse momento poderia ser benéfico.

Os docentes consideram a autoavaliação como um momento importante para o aluno, quando ele pode tomar cons- 
ciência plena de suas qualidades e defeitos. De igual forma, é uma oportunidade para corrigir erros, principalmente de ordem prática, ocasionando melhorias para o aluno e para o docente. Além da correção de erros, ela auxilia a identificar pontos fracos e fortes, contribuindo com o processo de aprendizagem contínua ${ }^{23}$.

Quanto à solicitação da autoavaliação referente ao aprendizado do aluno, vários $(61,11 \%)$ alunos e poucos $(31,81 \%)$ docentes relatam que o fazem, sendo que um número significativo de docentes $(54,54 \%)$ não adota essa prática. Um dos alunos relata que gostaria de reconhecer suas deficiências e intervir nelas a tempo, tendo sugerido que a autoavaliação fosse padronizada.

A autoavaliação é uma forma de se debruçar sobre a própria ação ou sobre si mesmo por meio de um olhar crítico sobre as fragilidades e potencialidades no caminho de formação tanto do discente como do docente. No âmbito da avaliação, ela favorece o aprendiz a se localizar no processo de ensino-aprendizagem, possibilitando a metacognição, que "é o conhecimento sobre o caminho de conhecimento que está percorrendo", bem como ajuda a desenvolver autonomia para buscar formas de superação do $\operatorname{erro}^{24}$ (p. 99).

Tratando-se de sua aplicabilidade, a autoavaliação se dá de forma não hegemônica no curso de Medicina estudado. Um dos fatores que contribuem para a sua não execução é o desconhecimento, pelos docentes, dessa importante ferramenta no processo de formação. Outro aspecto levantado é a subjetividade que a compõe, geradora de desconfiança por parte dos professores. Em algumas ocasiões, o docente solicita ao aluno que, além de se autoavaliar, dê uma nota ao próprio desempenho. Isto pode se tornar um fator impeditivo de crescimento em relação às demais estratégias. Quanto ao quesito valorativo, para se obter a sinceridade do aluno, a nota deve ser colocada à parte principalmente nas avaliações formativas, para não se vincular ao quesito de aprovação/reprovação ${ }^{24}$.

Dos docentes que não solicitam a autoavaliação, alguns $(27,27 \%)$ dizem que não o fazem por nunca terem pensado sobre esse tipo de avaliação e por terem alguma dificuldade em realizá-la.

Uma percepção importante que emergiu neste trabalho foi a de um professor que afirmou que sempre é dito que o professor é quem avalia e por isso não havia cogitado espaço para o aluno nessa atuação avaliativa.

É importante apontar que a temática da autoavaliação oferece ao docente uma reflexão sobre a aplicabilidade e a participação do aluno no contexto avaliativo como copartícipe de sua formação. Assim, a avaliação deixa de ser um papel exclusivo do professor.
Diante dos achados da pesquisa, reforça-se a discussão de que o processo de construção do conhecimento envolve tanto o aluno como o docente. Várias estratégias são usadas para avaliar o conhecimento adquirido. Por isso, revisitar a caminhada desse processo partindo do olhar do sujeito que a fez torna-se significante e capaz de suscitar mudanças relevantes tanto no ato de aprender como no ato de ensinar, favorecendo ambos os atores no cenário da formação.

Avaliação de habilidades (Osce) no internato: uma primeira aproximação

Novas metodologias de avaliação têm sido aplicadas no ensino da saúde a fim de atender especificidades dessa área do saber. Diante disso, a avaliação de habilidades pelo método Osce foi considerada objeto de diálogo no momento da entrevista com alunos e docentes.

Essa categoria surgiu devido à experiência vivenciada por uma parcela dos participantes da pesquisa numa avaliação de habilidades aplicada no internato de Clínica Médica em junho de 2015. Essa iniciativa foi muito relevante, mostrando o envolvimento do docente e o interesse em melhorar a formação dos futuros médicos. A experiência de aplicação do Osce foi significativa tanto para docentes como para discentes, mesmo requerendo aprimoramentos teóricos e práticos. Os docentes perceberam a importância desse método, que avalia as habilidades de "saber fazer" e "mostrar como se faz", habilidades importantes para o futuro profissional médico em seu cotidiano.

Quando questionados se conheciam, ouviram falar ou se tiveram alguma experiência com o Osce, metade (50\%) dos alunos e mais da metade dos docentes (55,54\%) afirmaram que desconheciam, não tinham experiência e somente tinham ouvido falar.

Em contrapartida, alguns dos alunos (33,33\%) disseram ter passado por uma experiência, e alguns docentes (31,81\%) afirmaram ter algum conhecimento sobre esse método avaliativo. Os docentes declararam que é um método prático com raciocínio clínico, que complementa a avaliação do aluno. Consideram que se trata de uma boa avaliação, pois existe um caso clínico que, ao ser padronizado e ter caráter objetivo, possibilita avaliar igualmente os alunos. Afirmaram também que esse método exige do aprendiz conhecimento para efetuar o raciocínio clínico e é importante para avaliar habilidades clínicas da prática médica. Assim, pode-se inferir que o raciocínio clínico e as habilidades clínicas remetem à avaliação de competências clínicas fundamentais, que "envolvem a tomada da história clínica, a realização do exame clínico, a interpretação dos achados no raciocínio clínico, e, sobretudo, a interação e a comunicação apropriadas com o paciente"2 (p. 298). 
Esse método, apesar de sua importância, apresenta alguns aspectos considerados problemáticos, inerentes a sua organização e execução. Alguns alunos $(27,77 \%)$ e poucos docentes $(31,81 \%)$ se manifestaram sobre isso. Um dos problemas citados foi o nervosismo vivenciado pelos alunos na prova prática, pois, embora o considerem um método interessante, reiteram ser altamente estressante.

De todos os participantes que se manifestaram sobre problemas relativos ao Osce, o nervosismo e o estresse aparecem relatados na fala de $27,77 \%$ dos alunos e de alguns docentes (13,63\%). Um dos motivos geradores do estresse é a aplicação de uma metodologia nova no curso de Medicina, tanto para os alunos como para os docentes, e que, por desconhecimento, acabou gerando demasiada pressão e tensão ligadas a essa avaliação.

Outro problema apontado foi a ausência de padronização do Osce efetuado, que colaborou para o estresse e nervosismo dos alunos, cansaço do professor e do aluno, além de não permitir uma avaliação similar para todos, por conta do tempo desigual entre as estações, variabilidade interobservador, diferentes critérios, diferentes tempos de avaliação entre as estações e procedimentos diferentes de avaliação.

Nesse sentido, salienta-se que o Osce exige planejamento minucioso, treinamento com os docentes e com os atores para calibragem dos procedimentos avaliativos, além de envolvimento de vários docentes, um lugar adequado para as avaliações e o comprometimento de todos os envolvidos. Nem sempre essas particularidades são fáceis de atender, o que pode comprometer grandemente a avaliação que se pretende fazer por se perder a padronização.

Além disso, o assunto cobrado na avaliação prática foi considerado em desacordo com o conteúdo teórico e prático transmitido no internato. A ausência de manequins para avaliar determinadas habilidades também dificultou a realização da prova prática pelo discente, exigindo-lhe utilizar sua imaginação para determinada situação, sem que tivesse recursos para isto.

A falta de padronização e a cobrança de um conteúdo que não havia sido discutido com o professor na teoria ou na prática foram prejudiciais ao aspecto emocional dos alunos e responsáveis pela desestruturação durante o Osce. A dinâmica do atendimento ao paciente e a grande rotatividade de situações no período do internato podem colaborar para que esse fato aconteça. Para evitar que isto ocorra, é necessário que o docente tenha atenção ao planejamento e organização do percurso transcorrido pelo aluno nesse importante espaço de formação.

A falta de manequim ou de paciente simulado prejudicou também o resultado pretendido na avaliação de habilidades clínicas. O estresse vivenciado no momento avaliativo impediu que o aluno imaginasse certos detalhes, repercutindo negativamente em seu desempenho.

Os problemas levantados são relevantes e mostram que o processo organizacional e de planejamento do Osce é imprescindível para que essa avaliação possa atingir o efeito desejado. Os apontamentos sobre falta de padronização, estresse e cansaço de alunos e docentes necessitam ser revistos, pois esses aspectos geram nervosismo e insegurança. A ausência de manequim é também uma situação que precisa ser mudada. No momento da avaliação, a presença de atores e/ou manequins é de grande importância, pois simula um paciente real. Deixar para o imaginário do aluno a elaboração dos sintomas e sinais do paciente, certamente, trará prejuízo ao processo avaliativo.

\section{CONCLUSÃO}

O processo avaliativo evidenciado neste estudo é realizado por professores que procuram avaliar o aluno lançando mão de diferentes procedimentos e instrumentos, em diferentes momentos, em atenção à avaliação integral do aluno em seus aspectos cognitivos, relacionais e de habilidades no "saber fazer" e no "ser". Embora tenha longa vivência com o ensino sistematizado, a grande maioria dos docentes apresenta importante lacuna principalmente quanto à avaliação em seus aspectos de elaboração, execução e utilização de alguns recursos avaliativos, como a autoavaliação, o feedback e a padronização.

O uso do feedback ainda se encontra em estágio embrionário, apesar de constituir uma interessante ferramenta no processo avaliativo por conta de seus benefícios no auxílio, tanto do aluno como do professor, na tentativa de melhorar a construção do aprendizado e de como avaliá-lo.

O médico professor percebe-se como aprendiz no processo avaliativo e tem a percepção de que a falta de domínio pedagógico para aprender e melhorar sua avaliação gera a necessidade de formação. Nesse contexto, há necessidade de avanços com a formação continuada do médico professor para auxiliar a vencer, com mais propriedade, o desafio que envolve o processo avaliativo em seu fazer docente.

Diante da complexidade do fenômeno avaliativo, um importante aspecto desvelado pelos participantes foi a percepção do objetivo da avaliação: aprender para a vida profissional, e não necessariamente para alcançar uma nota para aprovação.

Ressaltou-se neste estudo a importante percepção dos participantes de que o aprendizado permeia a intencionalidade de avaliar e beneficia ambos, professor e aluno, que estão no processo de ensinagem. Igualmente, o erro torna-se coadjuvante do aprendizado, sendo capaz de incentivar o aluno em sua progressão rumo ao objetivo almejado. 
Apesar da heterogeneidade dos docentes no processo avaliativo, há uma clara intencionalidade de avaliar adequadamente os futuros profissionais para se tornarem excelentes no atendimento aos pacientes.

O curso em estudo está em fase inicial na formação de novos médicos para a sociedade brasileira. O processo do ensino na saúde conta com professores que reconhecem a necessidade de unir os conhecimentos que a formação inicial lhes conferiu com os específicos da área pedagógica. A riqueza da integralidade das diferentes áreas do saber e suas repercussões nos atores no cenário do ensino são molas propulsoras rumo à formação de qualidade.

A avaliação, além de ser uma arte, é também um desafio e convida professores e alunos a deixar suas certezas e locais de conforto para explorar aquilo que ainda necessita de aprimoramento. E este aprimoramento se constrói quando alunos e docentes, juntos, compartilham olhares, percepções e sugestões rumo ao ensino e ao aprendizado de excelência.

\section{AGRADECIMENTO}

Agradecemos a Universidade Tecnológica Federal do ParanáCampus Ponta Grossa, pelo apoio recebido.

\section{REFERÊNCIAS}

1. Tempski, PZ.; Martins, MA. O papel da Avaliação de Habilidades Clínicas na Educação Médica no Brasil. In: Tibério, IFLC et al. org. Avaliação Prática de Habilidades Clínicas em Medicina. São Paulo: Atheneu; 2012. p 303-8.

2. Tibério, IFLC; Daud-Gallotti, RM. Experiência de Avaliação Prática Estruturada de Habilidades e Atitudes do Tipo OSCE no Internato. In: Tibério, IFLC et al. org. Avaliação Prática de Habilidades Clínicas em Medicina. São Paulo: Atheneu, 2012. p 297-302.

3. Harden, RM; Stevenson M; Downie WW; Wilson, GM. Assessment of Clinical Competence using objective structured examination. British Medical Journal. 1975; 1, p.447-451. Disponível em https://www.bmj.com/content/1/5955/447. Acesso em 09 de dezembro de 2018.

4. Shute VJ. Focus onformative feedback. Review of Educational Research. 2008;78(1)153-89. Disponível em http:/ / projects.ict.usc.edu/dlxxi/materials/Sept2009/Research\%20 Readings/Shute $\% 202008 \% 20$ Focus $\% 20$ on\%20formative\%20feedback.pdf Acesso em 09 de dezembro de 2018.

5. Machado, JLM. A participação da ANDES-SN na Cinaem: o processo de transformação das escolas médicas brasileiras. Interface (Botucatu), Botucatu, v. 3, n. 5, p. 177-180, ago.1999. [capturado 31 jul. 2018]. Disponível em http:// www.scielo.br/pdf/icse/v3n5/25.pdf
6. Haddad, AE; Brenelli, SL; Michel JLM; Nunes, MPT; Bucci, MPD; Campos, FE. A Educação médica no contexto da Política Nacional e Educação na Saúde. In Marins, JJ; Rego, S. orgs. Educação Médica: Gestão, Cuidado, Avaliação. São Paulo: Hucitec, 2011. p.19-41.

7. Glasser, BG.; Strauss, AL. The Discovery of Grounded Theory Strategies for Qualitative Research. $4^{\mathrm{a}}$ ed. Aldine Transaction. A Division of Transaction Publishers New Brunswick (USA) and London (UK). 2006. Disponível em http:/ / www.sxf.uevora.pt/wp-content/uploads/2013/03/Glaser_1967.pdf. Acesso em 04 de dezembro de 2018.

8. Bardin, L. Análise de conteúdo. Edições 70. Lisboa, Portugal, 2010.p.38

9. Batista, NA; Batista, SH. A docência em saúde: desafios e perspectivas. In Batista, NA; Batista, SH orgs. Docência em Saúde: temas e experiências. São Paulo: Senac; 2014. p 1727.

10. Seiffert, OMLB; Abdalla, IG. Avaliação educacional na formação docente para o ensino superior em saúde. In Batista, NA, Batista, SH, orgs. Docência em Saúde: temas e experiências. São Paulo: 2014. p. 149-167.

11. Luckesi, CC. Avaliação da aprendizagem: componente do ato pedagógico. 1a ed. São Paulo: Cortez, 2011. p.82,83.

12. Escudero E; Azul MAB. Construção de Guias para Baixa Fidelidade In. Neto, AS; Fonseca, AS; Brandão, CFS. Simulação Realística e Habilidades na Saúde. São Paulo: Atheneu, 2017. p 59-75.

13. Troncon, LEA. Avaliação do estudante de medicina. Simpósio de Ensino Médico de Graduação; 1996 out; Ribeirão Preto, p.429-39.

14. Conselho Federal de Medicina. Câmara Técnica do CFM trabalha em competência do clinico médico/internistas. 2018. [capturado 19 jun. 2018]. Disponível em https:/ / portal.cfm.org.br/index.php?option=com_content\&view=art icle\&id=27467:2018-03-01-18-47-09\&catid= 3 .

15. Gomes, AP; Arcuri, MB; Cristell, EC; Ribeiro, RM; Souza, LMB, Siqueira-Batista, R. Avaliação no Ensino Médico: o Papel do Portfólio nos Currículos Baseados em Metodologias Ativas. Rev Bras Educ Méd [online]. 2010. 34(3) [capturado 18 jun.2018]; 390-96. Disponível em http:/ /www. scielo.br/pdf/rbem/v34n3/08.pdf

16. Sonzogno, MC. Metodologias no ensino superior: algumas reflexões. In Batista, NA; Batista, SH org.Docência em Saúde: temas e experiências São Paulo: Senac. 2014, p. 69-79.

17. Troncon, LEA. Métodos Estruturados de Avaliação Prática de Competências Clínicas. In: TIBÉRIO, I. de FLC et al. (Org.) Avaliação Prática de Habilidades Clínicas em Medicina. São Paulo: Editora Atheneu, 2012 p. 55-73. 
18. Cury, HN. Análise de erros: o que podemos aprender com as respostas dos alunos. $2^{-}$ed. Belo Horizonte: Autêntica, 2018. p. 81-91.

19. Pinto, NB. O erro como estratégia didática: estudo do erro no ensino da matemática elementar. $2^{\underline{a} e}$. São Paulo: Papirus, 2009, p. 7-26.

20. Coutinho, V.; Martins, JCA; Pereira MF, Mazzo A. Feedback e Debriefing. In. Neto AS.; Fonseca, AS; Brandão, CFS. Simulação Realística e Habilidades na Saúde. São Paulo: Atheneu, 2017. p. 115-125.

21. Cortella, MS. Conselhos de Mário Sergio Cortella para ser um bom professor. 2014. [capturado em 26 jun 2018] Disponível em https://suburbanodigital.blogspot. com/2014/05/conselhos-de-mario-sergio-cortella-para-ser-um-bom-professor. htm

22. Zeferino AMB; Domingues RCL; Amaral E. Feedback como Estratégia de Aprendizado no Ensino Médico. Rev. Bras de Educ Méd.2007. 31 (2): 176 - 179.

23. Domingues, RCL; Amaral E.; Zeferino, AMB. Autoavaliação e avaliação por pares: estratégias para o desenvolvimento profissional do médico. Rev. Bras de Educ Méd [online]. 2007. 31(2) [capturado 1 ago. 2018]; 173-75. Disponível em: http://www.scielo.br/pdf/rbem/v31n2/07.pdf.

24. Vasconcellos, C. dos S. Avaliação da Aprendizagem: práticas de mudança por uma práxis transformadora. $8^{\underline{a}}$ ed. São Paulo: Libertad, 2006. p.229.

\section{CONTRIBUIÇÃO DOS AUTORES}

Marlene Harger Zimmermann: redação do artigo; Rosemari Monteiro Castilho Foggiatto Silveira: revisão, correção e aprovação para envio do artigo; Ricardo Zanetti Gomes: revisão e correção do artigo.

\section{CONFLITO DE INTERESSES}

Não há conflito de interesse por parte dos autores.

\section{ENDEREÇO PARA CORRESPONDÊNCIA}

Marlene Harger Zimmermann

Rua Sete de Setembro, 125 apartamento 42

84010-350 Ponta Grossa-PR

e-mail: marlene_hz@yahoo.com.br 